\title{
Ethical and cultural value of the Earth sciences Interview with Prof. Giulio Giorello
}

\author{
Silvia Peppoloni
}

\author{
Article history \\ Received December 21, 2011; accepted February 21, 2012. \\ Subject classification: \\ Geoethics, Earth sciences, Geological culture, Precautionary principle, Sustainability.
}

Prof. Giulio Giorello is amongst the most prominent philosophers of science in Italy and in the world. He is currently Professor of the Philosophy of Science at the University of Milan, Director of the Series 'Science and Ideas' (Raffaele Cortina Books Editor), and Literary Journalist of the cultural pages of the "Corriere della Sera", one of the most important of the Italian newspapers. In this keynote presentation, in interview form, he talks about the value that the Earth sciences have had through history, framing this group of disciplines in ethical and epistemological terms, and highlighting some important elements that have to be considered in geological activities.

\section{Silvia Peppoloni (S.P.)}

For some years, geoscientists have been talking about geoethics, pondering upon all the ethical, social and cultural aspects that are implicit in geological research and practice, because of the close link between Earth sciences and human life and activities. In this historical moment, the scientific community needs reference points to develop constructive debate and to frame geoethics in the correct way from an epistemological point of view. Starting from the cultural value of science and techno-scientific enterprise, 'Science is culture', as is maintained. Jules Henri Poincaré argues that "in virtue of science and art, civilizations have a value". Geology is a science, and as such it is culture, and therefore it can transfer cultural values to society, as first of all the value of its own territory. In your opinion, what is the civil value of the geologist's activities, and the geologist's social and individual responsibility?

\section{Giulio Giorello (G.G.)}

I repeat not only that science is culture, but I also add that Jules Henri Poincaré was right in saying that science is one of the characteristics that distinguish a civilization. Earth sciences are an example of authoritative sciences, which had and still have immense importance, especially from a cultural point of view, as well as from a technical point of view. The great geology of the 1800's and 1900's, the geology of James Hutton and Charles Lyell, two great Scottish geologists, opened the way for the cultural development of Charles Darwin's theory. Indeed, they introduced the fundamental 'Deep Time' concept: the Bible claims that the Earth is a few thousand years old, while James Hutton and Charles Lyell claimed that it was much older. This was the first step to a great intellectual revolution, which allowed Charles Darwin's theory to take off.

Geology, by full right, is part of the great science of the Enlightenment. Geology is a fundamental discipline of scientific enterprise. It has been the cause of great conflicts and controversies, and this is a good thing: when there is an intellectual clash, then there is the pleasure of discovery. Conflicts occurred also in the study of the sky with Copernicus, Galileo, Bruno, and Kepler, and with Newton, in the study of physics and chemistry. It was so also for geology. In the U.S., the Deep Time concept is still opposed by Creationists, who reject the whole cultural change that geology has produced, from the Enlightenment to today. So, geology is a fundamental part of scientific enterprise.

It all started in ancient times, with the watching of the sky, and also the observing of the Earth. The ancients tried to correlate events in the sky (such as eclipses) with great events on Earth. Today this may seem to us naïve, but it shows that the great civilizations of the past had already realized the importance of studying the sky and the Earth. We find this attitude in Mesopotamia, and also in India and China, and within some pre-Columbian civilizations. If we look at the past, we see that civilization has gone through geology, to try to understand the Heavens above us, and also the Earth beneath us.

\section{S.P.}

Many years ago, Giuseppe Grandori, an Italian Professor emeritus who recently passed away, and one of the most distinguished scientists in the field of earthquakes, said: "Defending oneself against earthquakes means to reduce the consequences of 
earthquakes (victims and material damages) below a limit that society deems acceptable, given the costs that would result by a further decrease of this limit". Grandori said this when nobody was talking about civil protection and emergencies yet. What can you say about the precautionary principle in relation to Earth sciences?

\section{G.G.}

This statement of Grandori expresses much wisdom, as the best of our good sense. Scientific enterprise is nothing more than an extension of good sense, which is not intended as conformism, but as the ability to assess the costs of a technology, together with its benefits. A technology can appear expensive now, but everything must be assessed by looking at the probable outcomes of an investment strategy.

If there not had been the great geology of the past, and if there were no the current efforts of geologists, today we would be far behind in terms of civil protection and rational planning of the environment.

This quote from Grandori illustrates well the way to proceed in all of the applied sciences. The same can be said for medicine, when we take precautions against the risk of infections, or for engineering, navigation techniques, and others. In every discipline, there are always elements of risk. John Locke, an English philosopher and physician, wrote that we take our decisions under conditions of uncertainty, and therefore of risk. We cannot think of a perfectly safe technology, because 'absolute' is not a condition of our world. If we only act when we are sure that there is no risk, we would not even go out of our house, because we would not have the certainty about the risk of a tile hitting us on the head.

In all sciences, there is always uncertainty, and under conditions of uncertainty, we have to take our decisions. It is impossible to act with absolute certainty.

The precautionary principle in an absolute sense cannot operate. Demand for a technology to be put into operation without risk is a metaphysics call. We have to take risks, but risks must be balanced with a calculation; this is what Grandori highlighted. I am against the absolutist use of the precautionary principle to stop forms of scientific experimentation, as used by some fundamentalists or by reactionary philosophers.

I think that the fear of technology in itself is a dull and reactionary attitude. Working in fear is not worthy of a civilized human being. We have to face fear, and the fear should not be denied; it should always be used to understand how to move rationally. For the assessment of risks, we have to use the calculus of probability. We have this tool to assess risks and to see which policies are more or less rational. This is what Pascal teaches us, and also the Jansenists, who claimed that the calculus of probability is essential to determine our conduct. For example: if a man is afraid of lightning, but he is economically motivated and knows in addition that studies of probability indicate that only one man in a million is hit by lightning, then he wins over his fears, and he leaves the house even if it is raining.

Moreover, we see that some risks of scientific research are much lower than others. It is much more dangerous going out with the car and driving on the highway during the weekend. We must accustom ourselves to living in an uncertain world. As John Locke said, "We take our decisions in the twilight of probability, and not into the clear light of certainties". However, using the calculus of probability, we can do the best we can, as Grandori said.

The eminent Italian mathematician Bruno De Finetti, theorist of subjective probabilities, always cites geology as an example of a discipline in which the problem of uncertainty is always present: to know how to handle this can give us great satisfaction.

\section{S.P.}

Based on these considerations, the concept of sustainability, which contains in itself the concept of time, in terms of continuity and long-term use of a resource, how has this to be understood?

G.G.

The concept of sustainability is implicit in the sentence of Grandori. There is no sustainability in an absolute sense. The balance between cost and benefit is fundamental, and it can change over time, as well as our intuitions about what we want to achieve or not to achieve. It is important to be clear. A few decades ago, bioethics was born, with the aim to assess the advantages and disadvantages of research on human life and to understand how this research can be directed at improving the quality of life. Today bioethics has become the cause of a clash between different stances of ideological, political and religious positions. This is beyond what the founders had in mind. I hope that geoethics does not go in this same direction, and instead remains a sober discipline, that looks primarily at the ethical significance of the correct knowledge of the world we live in.

Philosophy, born as cosmology, is not a mere intellectual exercise, but a way of life. I believe that the Earth sciences can better explain to us how our common home works, indicating the ways to deal with natural disasters, which are often triggered by humans, and therefore refer to human responsibility.

The Lisbon earthquake of 1755, which was an event that shook the conscience of the Enlightenment, including intellectuals like Voltaire and Kant, destroyed entire neighborhoods and left others intact, for example, the Arab quarter. This highlighted the differences in the expertise of those who had built at different times. Building safely is an ethical responsibility. 


\section{S.P.}

Plato opposed episteme, the science based on knowledge, to doxa, the opinion of the people. I ask you for a reflection on the L'Aquila earthquake. On that occasion, maybe there was a mixing of many elements: disagreement across scientific knowledge, deemed more or less authoritative, and media sensationalism, and the pain and dismay of the citizens of L'Aquila, and inside us, as earthquake researchers, the feelings of impotence and uselessness. How can we combine the rigor and the determinism of scientific research with wise and operational good sense, that can reassure the population in case of alarm? Perhaps this should be a responsibility that scientists have to assume; or maybe not?

\section{G.G.}

Today, we have little faith in scientific certainty, that is Plato's episteme; we are accustomed to work more on our opinions. But opinions should not be despised. "The opinions are our consciousness that is being formed", as the English poet John Milton wrote during the Civil War in England in the 17th century. Opinions must be evaluated through comparison and intellectual exchange if we want them to be valid and not to be shocked by emotion. The challenges of nature are continuous.

I believe that in the tragedy that occurred in L'Aquila, it is necessary to start from the legitimate discomfort of citizens, from their pain and suffering, which cannot be removed. The media, subservient to political power, have striven to show the politicians as 'saviors of the country'. Politicians should be servants of the State and citizens. In our country, [Italy,] we are discovering acts of awareness of whole categories. If the politicians do not serve the citizens, they must be driven out. If the citizens say "No!" to those who govern us, this will also help scientists: science is allied with democracy. If politicians do not take into account these aspects, they become dictators, and against dictators there are very specific methods that can be used, as the legitimate fight against the iniquity of a power that does not take into account first of all the interests of the health and safety of the citizens.

\section{S.P.}

Referring to the relationship between science and politics in the Italian context, sometimes we might think that our politicians appear far from an understanding of the importance of scientific research as a tool to serve the citizens, considering it only a mere speculative exercise. A recent example in Italy is the referendum on nuclear energy. Beyond the ideas that somebody might have about this, do you think that a clear debate on the limits and potentials of this technology has been completely missed?

\section{G.G.}

With regard to nuclear power, it is an interesting case of shilly-shallying and indecision. I think there have been many missed opportunities in the past; now the situation is so intricate that any choice might be wrong. A debate on nuclear power had to be carried out 40 years ago, avoiding being drawn into a strong emotional impact. At the time of the Chernobyl disaster, it had to be said that the tragedy was due to the age of the structures. Personally, I am not a supporter of nuclear power, but I think that information for the citizens should be increased in Italy. We have a cultural lag in science, whereas in other cultural sectors, we are ahead.

We must take advantage of the excellence of the many Italian scientists who have reached very high levels of skill and are always available to provide their expertise in a frank, honest and democratic debate. My idea of democratic debate is very far from the miserable calculations made by political parties in Italy, both of the right and left political parties, as there is not much difference, with a very low level of demagoguery.

\section{S.P.}

One last reflection, on the women who dedicate themselves to science. Without going deeply into the theme of discrimination, which still today in the 21st century appears difficult to overcome in our society also in the sector of scientific research: perhaps the intelligence of women, the intuitive capacity and the good sense that often distinguishes them, is an unexploited potential. What do you think about this?

G.G.

When we talk about the role of women in scientific research, my thoughts go to Lise Meitner, the nuclear physicist who lived in the 1900's, a collaborator of Max Planck. She received no recognition, despite her contribution to the development of the theories about nuclear power. She was discriminated against not only because she was a woman, but also because she was Jewish, and for her political beliefs. My thoughts go to Rosalind Franklin, who contributed to the studies about DNA; only after her death was the Nobel Prize given to the other members of the team, the males, for the discovery of the DNA double helix. Somebody said she had a bad temper. We are still under the silliness of judging a woman who works in research by her character, and not by the greatness of her scientific discoveries! So, in the same way, we should erase Newton from history, who had a notorious bad temper. We have to be careful. The difficult integration of women is not a biological or psychological problem, as some argue, but it is a question of discrimination and social oppression. Women should be able to do more than what they do, even in science, as well as in the political field, to gain proper recognition. When there is discrimination, the shame is expanded also to those who are not a part of this discrimination. "Every wrong done against my brother or my sister is done against me": this is the principle which 
should lead us to remove any obstacle, and to use the injection of energy that comes from the presence of women in science and technology.

\section{S.P.}

To conclude: Karl Popper says that it is possible to talk even among people who do not share common values; the debate and the language can be built along the way. But then, is it possible to identify a common value, an ethical criterion on which to base the study of our Planet? What principle should guide us in geological research and practice, and what, as geologists, can we do to increase the motivation and sense of responsibility that our work implies?

\section{G.G.}

I agree with this wonderful statement of Popper. If there had been no Tower of Babel, it would have been necessary to invent one. The differences in points of view, in languages, in the conceptual apparatus, are resources and not defects in scientific research. Contrasts are necessary, especially in the field of scientific research. If we clash over a problem, as Galileo said, science takes advantage from this. He was right, even if he paid for his autonomy of thought, for his intellectual freedom, with the shameful processes that silenced him.

It is dangerous for scientific enterprise to silence the dissent. False consensus is unmasked in the long run, and scientific truth comes out in the end. One of the most beautiful and tragic histories inside geology regards the wonderful figure of Alfred Wegener, a scholar who defined the theory of continental drift. He was mocked by his contemporaries, despite the deep and refined articulation of his theory, and this caused legitimate resentment in him. He died as a lone hero on an expedition to the Pole. But decades after, his theory was reconceptualized, and has become one of the great revolutions within the Earth sciences, which then led to the theory of plate tectonics. This story shows that those who dare to disagree, in the end are right. Intellectual tolerance and openess to the proliferation of multiple points of view is a boon to science. There were similar vicissitudes in quantum physics: the clashes between Einstein and Bohr were useful to refine the theory, and from these discrepancies were born beautiful works.

Geology has its epic stories too, full of ethical implications. Ethics means an attitude that aims to reduce the suffering of the world in a reasonable way, and to intervene with the environment in a controlled and responsible way. In the book of Bill McGuire, who teaches in one of the most prestigious British universities, entitled 'A guide to the end of the world', there is no history of apocalyptic prophecies, for which we care very little. Instead, there is an analysis of our responsibilities to avoid the disasters that can have serious consequences on the global economy. There is a chapter on earthquakes, which shows how the wrong choices of governments and their disregard of geological problems can have heavy repercussions. This shows all the stupidity of the political class.

The issues are complex, and geology can help in this complexity. Geology is like a red thread that allows us to move ahead: let us make geology as strong as possible!

It is important to talk about geology in schools, to make young people aware of the importance of knowing the Earth. Moreover, we have to tell the heroic stories of geoscientists, like James Hutton, Charles Lyell, John Tuzo Wilson, and many more, who are worthy enough to stand alongside the best-known figures, such as Einstein, Copernicus and Galileo.

\section{S.P.}

Thank you, Professor, for the recognition of value that you have given to the Earth sciences and for having framed this group of disciplines in ethical and epistemological terms.

Corresponding author: Silvia Peppoloni, Istituto Nazionale di Geofisica e Vulcanologia, Rome, Italy; email: silvia.peppoloni@ingv.it.

(C) 2012 by the Istituto Nazionale di Geofisica e Vulcanologia. All rights reserved. 